\section{OPEN ACCESS}

Edited by:

Miroslav Harjaček

Sisters of Charity Hospital, Croatia

Reviewed by:

Thaschawee Arkachaisri, KK Women's and Children's Hospital, Singapore

Gerd Horneff

Asklepios Clinic Sankt

Augustin, Germany

*Correspondence:

Ilaria Pagnini

ilaria.pagnini@meyer.it

Specialty section:

This article was submitted to

Rheumatology,

a section of the journal

Frontiers in Medicine

Received: 12 February 2021

Accepted: 19 April 2021

Published: 13 May 2021

Citation:

Pagnini I, Scavone M, Maccora I, Mastrolia MV, Marrani E, Bertini F, Lamot $L$ and Simonini $G$ (2021) The

Development of Extra-Articular

Manifestations in Children With Enthesitis-Related Arthritis: Natural Course or Different Disease Entity?

Front. Med. 8:667305

doi: 10.3389/fmed.2021.667305

\title{
The Development of Extra-Articular Manifestations in Children With Enthesitis-Related Arthritis: Natural Course or Different Disease Entity?
}

Ilaria Pagnini ${ }^{1 *}$, Mariangela Scavone ${ }^{1}$, Ilaria Maccora ${ }^{1}$, Maria Vincenza Mastrolia ${ }^{1}$,
Edoardo Marrani ${ }^{1}$, Federico Bertini ${ }^{2}$, Lovro Lamot $^{3}$ and Gabriele Simonini ${ }^{1}$

${ }^{1}$ Rheumatology Unit, Meyer Children Hospital of Florence, University of Florence, Florence, Italy, ${ }^{2}$ Radiology Unit, Meyer Children Hospital of Florence, Florence, Italy, ${ }^{3}$ Department of Pediatrics, School of Medicine, University of Zagreb, University Hospital Centre Zagreb, Zagreb, Croatia

Introduction: Enthesitis-related Arthritis (ERA) is a specific category of juvenile idiopathic arthritis (JIA) characterized by axial and/or peripheral arthritis, and enthesitis, although other different extra-articular manifestations may encompass its clinical spectrum.

Materials and Methods: In order to examine if ERA-JIA with extra-articular involvement may represent a different entity from ERA without extra-articular involvement, we performed a retrospective, observational, monocentric study, in a cohort of ERA patients followed between 2001 and September 2020 at the Pediatric Rheumatology Unit of Meyer Children Hospital of Florence. We analyzed the demographic, clinical, laboratory and imaging data at the disease onset, as well as after 3, 6, and 12 months follow up.

Results: We have enrolled 53 patients, 33 males. At the time of diagnosis, average age was 10.9 years, 53 patients had active arthritis and 25 active enthesitis. The middle foot involvement was present in 20 patients. Twenty-five children achieved clinical remission on medication. Extra-articular manifestations were observed in 14 patients, of whom 3 had inflammatory bowel disease, 5 uveitis, one uveitis associated with Crohn disease, 4 SAPHO syndrome, one celiac disease. The cohort was stratified according to the presence/absence of extra-articular manifestations. It was observed that middle foot involvement was more frequent in patients with no extra-articular manifestations (18/39 vs. $2 / 14 ; \chi^{2}=4.45, p=0.05$ ). Additionally, patients presenting extra-articular manifestation needed more frequently $\left(12 / 14\right.$ vs. $21 / 39, x^{2}=4.45, p$ $=0.05$ ), and preciously (months: $3.7 \pm 5.4$ vs. $16.7 \pm 26.5, p=0.02$ ), treatment with biologic agents. Finally, these patients achieved belatedly (months: $31.6 \pm 32.3$ vs. $22.9 \pm 18.3, p=0.01)$ and less frequently $\left(3 / 14\right.$ vs. $22 / 39 ; \chi^{2}=5.50, p$ $=0.03)$ the clinical remission on medication. Eventually, extra-articular involvement inversely correlated with the middle-foot arthritis $\left(\rho_{\mathrm{s}}-0.29, p=0.03\right)$, the chance to achieve remission on medication $\left(\rho_{\mathrm{s}}-0.31\right.$ e $\left.p=0.02\right)$, as well as the chance to keep overall remission, with and without medication ( $\left.\rho_{\mathrm{s}}-0.28, p=0.04\right)$. 
Conclusion: In our cohort, children diagnosed with ERA-JIA at the onset of disease and then developed extra-articular manifestations show the absence of middle foot involvement and worse prognosis with an early need for the use of biologic agents, and overall low chance to achieve remission.

Keywords: enthesitis-related arthritis, extra-articular, midfoot, biologic, sacroiliitis, children, JIA

\section{INTRODUCTION}

Enthesitis-related Arthritis (ERA) is one of the more common types of Juvenile Idiopathic Arthritis (JIA) (1), frequently affecting males after 6-year-old. In Europe and North America, ERA comprises almost $10 \%$ of JIA cases $(2,3)$ as opposite to certain countries in Asia where it represents the most common JIA subtype (35-40\% of JIA patients) (4-7). The main findings of this particular JIA subtype are axial and/or peripheral arthritis, inflammatory back pain, enthesitis and a specific association with the HLA-B27 typing.

While the criteria of International League of Associations for Rheumatology (ILAR) are most commonly used by pediatric rheumatologists to classify this entity in children, ERA patients are often regarded as having an undifferentiated form of juvenile spondyloarthritis (jSpA) $(1,8)$. However, as opposite to ERA, jSpA encompasses differentiated forms such as juvenile ankylosing spondylitis (jAS), psoriatic arthritis (PsA), reactive arthritis $(\operatorname{ReA})$ and arthritis associated with inflammatory bowel disease (IBD), as well (8). Moreover, different extra-articular manifestations, such as uveitis inflammatory bowel disease, celiac disease, Synovitis Acne Pustulosis Hyperostosis Osteitis (SAPHO) syndrome or less common cardiac and/or pulmonary involvement may encompass jSPA spectrum. Conversely to other JIA subtypes, uveitis in ERA patients is typically characterized by an acute, symptomatic onset with red, painful, and photophobic eye, usually unilateral and frequently recurrent $(9,10)$. Inflammatory bowel disease, including Crohn disease, ulcerative colitis and undifferentiated colitis, occurs in 5-10\% of patients affected by ERA, more frequent in males, at the onset or during disease course (11). In addition, celiac disease occurs in $1-8 \%$ of patients with ERA (12), while SAPHO syndrome is an even less frequent complication characterized by axial involvement along with enthesitis and peripheral arthritis and typical cutaneous findings $(13,14)$.

Although uncommon, aortic insufficiency as well as myocarditis, endocarditis and pericarditis, often with spontaneous resolution, can occasionally occur in ERA patients (15-17). Pulmonary involvement, characterized by diminished chest expansion with decreased vital capacity, are very rare $(18,19)$, whilst central nervous system (CNS) diseases are seldom reported in ERA (19).

In order to define the clinical phenotype of ERA-JIA with extra-articular features, we enrolled patients affected by ERA and stratified them by the presence of extra-articular manifestations. Moreover, to address if ERA-JIA with extra-articular involvement may represent a different entity from ERA without extra-articular involvement, we compared the clinical features, laboratory data, treatment modalities, disease activity and outcome of a pediatric cohort of ERA-JIA patients.

\section{MATERIALS AND METHODS}

We performed a retrospective, observational, monocentric study, in a cohort of patients affected by ERA and followed between 2001 and September 2020 at the Pediatric Rheumatology Unit of Meyer Children's University Hospital in Florence.

All patients fulfilled the International League of Associations for Rheumatology (ILAR) criteria $(1,20)$ for the diagnosis of ERA-JIA. We analyzed the demographic, clinical, laboratory and imaging data at the disease onset, and thereafter at 3, 6, and 12 months follow up. All data were enrolled in a customized database, including:

- Demographic variables: (1) gender; (2) age at the onset of clinical manifestation; (3) age at the diagnosis, entered as the age the child met the (ILAR) criteria for ERA; (4) history of HLA-B27-related disease in first-degree relatives, including ankylosing spondylitis, ERA, inflammatory bowel disease, reactive arthritis (Reiter's syndrome), and acute anterior uveitis. Psoriasis was excluded since is a mandatory exclusion criterion for ERA diagnosis if present in patient and/or in a first-degree relatives.

- Clinical variables: (1) disease duration; (2) interval between disease onset and diagnosis; (3) assessment of the number and type of affected joints. Active arthritis was defined as a joint with swelling not caused by bone enlargement, or limitation of motion in combination with pain or tenderness; (4) assessment of the number and type of affected enthesis. Enthesitis was defined as discretely localized tenderness at the point of insertion of ligaments, tendon, joint capsules, or fascia to bone (21), and assessed according to the Maastricht Ankylosing Spondylitis Enthesitis Score (MASES), but including in additional plantar fascia and calcaneus enthesis (22); (5) middle foot involvement, mono or bilateral; (6) inflammatory back pain, defined according to the Assessment of Spondylarthritis International Society (ASAS), expert criteria (23), as lumbosacral spinal pain persisting at least 3 months in patients with: age $<40$ years, insidious onset, improvement with exercise, not improved with rest, pain at night (at least 4 of 5 requirements need to be present) $(21,23)$; (7) tenderness of sacroiliac (SI) joints, compression of pelvis, distraction of the SI joints by Patrick's test $(21,23)$; (8) limited anterior spinal flexion, assessed by the modified Schoeber test (23); (9) limited lateral spinal flexion, according to the ASAS expert criteria (23); (10) extra-articular features, at the onset or 
during disease course (range was referred in months): uveitis, diagnosed by slit lamp examination; inflammatory bowel disease diagnosed by endoscopy and; celiac disease, diagnosed by laboratory test (antigliadin antibody, ant-transglutaminasis antibody detected by Enzyme-linked immunosorbent assay [ELISA] and anti-endomision antibody detected by Immunofluorescence [IFI]) and by biopsy of duodenum tract; SAPHO syndrome was diagnosed by the presence of the key clinical features; (11) Disease activity measures, according to the American College of Rheumatology pediatric criteria (24); (12) Disease remission indices, according to the preliminary criteria for clinical remission in JIA (25), including no active entheses.

- Laboratory variables: Hemoglobin value (Hb), erythrocyte sedimentation rate (ESR), C-reactive protein (CRP), presence of the HLA-B27 allele, and anti-nuclear antibody (ANA) positivity.

- Imaging SI assessment: Magnetic resonance imaging (MRI) study of the SI joints: dynamic contrast-enhancement MRI before and after administration of contrast medium was performed as described $(26,27)$. In all patients MRI images were obtained with a 1.5 Tesla unit (Philips Intera: Philips, Eindhovenn, The Netherlands) using a pelvic array body coil with reg following sequences: semicoronal Short tau inversion recovery (STIR) sequences, semiaxial Turbo spin echo (TSE) T1-weighted sequences, semicoronal Spectral Presaturation with Inversion Recovery (SPIR) T1-weighted sequences, semiaxial TSE T2-weighted sequences, semicoronal dynamicc T1fat-saturated (FS), and semiaxial T1 SPIR after administration of intravenous gadolinium $(0.1 \mathrm{mmol} / \mathrm{kg})$. Assessment of the MRI examinations included a grading of 0-3 (0 normal, 1 minimal, 2 moderate, 3 severe) of the following findings: erosion, sclerosis (low signal intensity on T1and/or T1 FS), bone marrow edema (high signal intensity in STIR), contrast enhancement in the bone and in the joint space, and joint space narrowing and/or Widening. All assessment and grading were performed at four anatomical sites for each SI joint: the sacral and iliac sites of the cartilaginous and ligamentous portions go the joint. In addition, gadolinium contrast enhancement was performed and acute/active sacroiliitis on MRI was defined if bone marrow edema on STIR or bone marrow osteitis on T1 post-gadolinium was detected and located in subchondral or periarticular bone marrow (28). Moreover, monolateral and bilateral sacroiliitis was graded $0-4$ corresponding to the New York criteria, according to Aarhus criteria accepted by Outcome Measures in Rheumatoid Arthritis Clinical Trials (OMERACT) Rheumatoid Arthritis Magnetic Resonance Imaging Scoring System (RAMRIS) (29);

- Therapeutic variables, as therapy administered at onset and throughout the disease course in terms of Disease-modifying anti-rheumatic drugs (DMARDs) and/or biologic treatment.

\section{Statistical Analysis}

All results were expressed as mean and standard deviation (SD), or median and range. Mann-Whitney $U$ test, Kruskal-Wallis test, Wilcoxon signed-rank test for paired samples, chi-square test $\left(\chi^{2}\right)$ and Fisher exact test, when appropriate, were used to compare data. Pearson and Spearman correlation tests were used to determinate correlation coefficients for different variables (sex, age at diagnosis, number of active joints at diagnosis, number of active enthesis at diagnosis, middle foot involvement, inflammation of SI joints, increased ESR, increased CRP, ANA positivity, HLA-B27 positivity, DMARDs treatment and timing of therapy, biologic treatment and timing of therapy, remission time). Multiple stepwise regression was performed to determine variables that could correlate independently with the development of extra-articular involvement and a confirmed diagnosis of ERA at last available follow-up. The predictors used in the final model were those showing a significant correlation in the univariate analysis. Non-parametric tests were used, where necessary, due to the small size of our groups and to the skewness of data. A p level $<0.05$ was considered statistically significant. All analyses were performed on SPSS for MAC, version 26.0 (SPSS Inc., Chicago, IL, USA).

\section{RESULTS}

Fifty-three children fulfilled the criteria for ERA at the time of diagnosis and were then enrolled into the study: 33 males and 20 females with a median age at diagnosis of 10.9 years (range 3-16 years). Except for eight patients, all children were Caucasian. This represents $10 \%$ of the total cohort of patients with JIA followed in our center in the same period.

As regards family history, the presence of an autoimmune disease (Ankylosing Spondylitis, Rheumatoid Arthritis, Hashimoto thyroiditis, type 1 Diabetes Mellitus, celiac disease, vitiligo and inflammatory bowel disease) was described in 23 subjects (43.4\%) of whom five reported multiple autoimmune disease.

At diagnosis, active arthritis was observed in all 53 children, whilst enthesitis, SI involvement and the middle foot in 25 (47.2\%), 23 (43.3\%), and 20 (37.7\%) patients, respectively. Table 1 details the clinical features, laboratory parameters and therapeutic approaches in our cohort of ERA-JIA patients.

At last available follow-up (median time from disease onset 42 months, range: $4-193), 25$ patients (47.2\%) reached clinical remission on medication after a median time of 14 months (range 6-62). Clinical remission on medication lasted for a median time of 67 months (range 9-142). Fifteen patients (28.3\%) reached clinical remission without medication for a median time of 16 months (range 6-35).

Over the disease course, 14 patients $(26.4 \%)$ developed extraarticular manifestations, which were not present at diagnosis but complained during the clinical course. In particular three patients had inflammatory bowel disease, one child had acute anterior uveitis associated to IBD, five patients had uveitis, four patients had SAPHO syndrome, and one patient had celiac disease. The mean time between ERA-JIA diagnosis and the extra-articular manifestation onset was 18.8 months (range 960). In three subjects, extra-articular symptoms (uveitis) were concomitant at the time of ERA onset and diagnosis. Thus, once the patients developed a confirmed diagnosis of IBD, 
TABLE 1 | Clinical features, laboratory parameters and therapeutic approaches of our cohort of diagnosed as ERA-JIA at the onset of disease.

\begin{tabular}{|c|c|c|c|}
\hline Clinical features & $\mathrm{N}$ of pts & $\begin{array}{l}\text { Non-extra- } \\
\text { articular } \\
\text { involvement }\end{array}$ & $\begin{array}{c}\text { Extra- } \\
\text { articular } \\
\text { involvement }\end{array}$ \\
\hline Arthritis at diagnosis & 53 & 39 & 14 \\
\hline - Symmetrical involvement & 18 & 12 & 6 \\
\hline - Asimmetrical involvement & 35 & 27 & 8 \\
\hline - Oligoarticular & 33 & 22 & 11 \\
\hline - Polyarticular & 20 & 17 & 3 \\
\hline Enthesitis at diagnosis & 24 & 20 & 4 \\
\hline - Monolateral involvement & 13 & 12 & 1 \\
\hline - Bilateral involvement & 11 & 8 & 3 \\
\hline \multicolumn{4}{|c|}{ Number of enthesitis at diagnosis } \\
\hline - One & 13 & 12 & 1 \\
\hline - Two & 8 & 6 & 2 \\
\hline - Three & 2 & 1 & 1 \\
\hline - Four & 1 & 1 & - \\
\hline Sl involvement & 23 & 16 & 7 \\
\hline - Monolateral & 18 & 12 & 6 \\
\hline - Bilateral & 5 & 4 & 1 \\
\hline Middle foot involvement & 20 & 18 & 2 \\
\hline - Monolateral & 20 & 18 & 2 \\
\hline - Bilateral & 7 & 7 & - \\
\hline \multicolumn{4}{|l|}{ Laboratory values } \\
\hline Increased ESR & 27 & 19 & 8 \\
\hline [mean value $\pm \mathrm{SD}(\mathrm{mm} / \mathrm{h})]$ & $37.1 \pm 29.6$ & $36.1 \pm 30.9$ & $40.1 \pm 26.2$ \\
\hline Increased CRP & 27 & 20 & 7 \\
\hline [mean value $\pm \mathrm{SD}(\mathrm{mg} / \mathrm{dll})]$ & $2.26 \pm 2.9$ & $2.17 \pm 3.1$ & $2.51 \pm 2.9$ \\
\hline Anemia & 12 & 9 & 3 \\
\hline$[\mathrm{Hb}$ mean value $\pm \mathrm{SD}(\mathrm{g} / \mathrm{dl})]$ & $10.0 \pm 1.4$ & $9.9 \pm 1.3$ & $10.3 \pm 1.2$ \\
\hline ANA positivity & 16 & 11 & 5 \\
\hline HLA B27 positivity & 21 & 18 & 3 \\
\hline \multicolumn{4}{|l|}{ Therapeutic approach } \\
\hline DMARDs & 48 & 37 & 11 \\
\hline - Methotrexate & 28 & 37 & 10 \\
\hline - Sulfasalazine & 20 & 19 & 1 \\
\hline Biologic agents & 33 & 21 & 12 \\
\hline - Adalimumab & 23 & 14 & 9 \\
\hline - Etanercept & 8 & 5 & 3 \\
\hline - Golimumab & 1 & 1 & - \\
\hline - Abatacept & 1 & 1 & - \\
\hline
\end{tabular}

SI, sacroiliac; ESR, erythrocyte sedimentation rate; CRP, C reactive protein; $H b$, hemoglobin; ANA, antinuclear antibodies; DMARDs, disease modifying anti-rheumatic drugs.

documented by typical histopathology then that affected patients have been classified as IBD-associated arthritis. The same for children at disease onset classified as ERA and later on as SAPHO syndrome due to the development of additional clinical findings. Therefore, eight (15\%) children did not fulfill anymore the ERA diagnosis.

Persistent arthritis was the indication for the biologic treatment, along with the development of uveitis, IBD and SAPHO syndrome in the cohort who exhibited over the disease course extra-articular involvement. Among these 14 children, two children, one with coeliac disease and one with uveitis, did not receive biologic treatment.

Moreover, of the 23 patients affected by sacroiliitis in ERA, 13 patients were in treatment with DMARDs (12 with sulphasalazine and 1 with Methotrexate), while 10 patients were in treatment with anti-TNF alpha inhibitors. Of these 10 patients, 7 developed extra-articular manifestation. In particular: two patients developed acute anterior uveitis, one patient developed gastrointestinal involvement, one patient developed celiac disease and three patients developed SAPHO syndrome. Eventually, among 23 children with sacroiliitis, 4 out of 23 (17\%) did not fulfill anymore the ERA diagnosis.

Patients' stratification according to the presence/absence of extra-articular manifestations revealed that the middle foot involvement was more frequent in patients without extraarticular manifestations (18/39 vs. $2 / 14 ; \chi^{2}=4.45, p=0.05$ ). Additionally, patients presenting extra-articular manifestations needed more frequently (12/14 vs. $\left.21 / 39, \chi^{2}=4.45, p=0.05\right)$, and preciously (months: $3.7 \pm 5.4$ vs. $16.7 \pm 26.5, p=0.02$ ), treatment with biologic agents (Figure 1). Moreover, this group of patients achieved less frequently ( $3 / 14$ vs. $22 / 39 ; \chi^{2}=5.50$, $p=0.03$ ) and belatedly (months: $31.6 \pm 32.3$ vs. $22.9 \pm 18.3, p$ $=0.01$ ) the clinical remission on medication (Figure 2). Overall, considering all the children on clinical remission at last available follow-up, including patients receiving and stopped treatment, this group of patients had less chance to maintain remission ( $4 / 14$ vs. $26 / 39: \chi^{2}=6.08, p=0.01$ ) (Table 2).

Eventually, extra-articular involvement inversely correlated with the middle-foot arthritis $\left(\rho_{s}-0.29, p=0.03\right)$, the achievement of remission on medication $\left(\rho_{\mathrm{s}}-0.31 \mathrm{e} p=0.02\right)$, as well the chance to keep remission, with and without medication $\left(\rho_{s}-0.28, p=0.04\right)$

No further correlations considering the number of active joints, the number of enthesitis, the presence of SI, the elevation of inflammatory markers, ANA and HLA-B27 positivity, type and duration of treatment with DMARDs were detected. In multiple regression analysis, where the development of extra-articular involvement at last available follow-up was set as dependent variable, the middle foot involvement and the clinical remission on medication remained as negative predictors of extra-articular involvement (multiple $\mathrm{R}=0.41$, multiple adjusted $\mathrm{R} 2=0.14, \mathrm{~F}: 5.19$, $p<0.009$ ).

Considering that eight children, four with IBDs and four with SAPHO syndrome, did not fulfill anymore the criteria for ERAJIA over the disease course according ILAR classification, we additionally performed a sub-analysis limited to the 45 ERAJIA children who fulfilled the diagnosis of ERA according ILAR criteria even over the diseases course.

The same statistical significance findings have been detected regarding the middle foot involvement: it was more frequent in patients without extra-articular manifestations ( $18 / 39$ vs. $0 / 6 ; \chi^{2}$ $=4.61, p=0.03)$, and extra-articular involvement in ERA-JIA inversely correlated with the middle-foot arthritis $\left(\rho_{\mathrm{s}}-0.32, p=\right.$ 0.03 ). Conversely, the others statistical significance results have not been kept. 


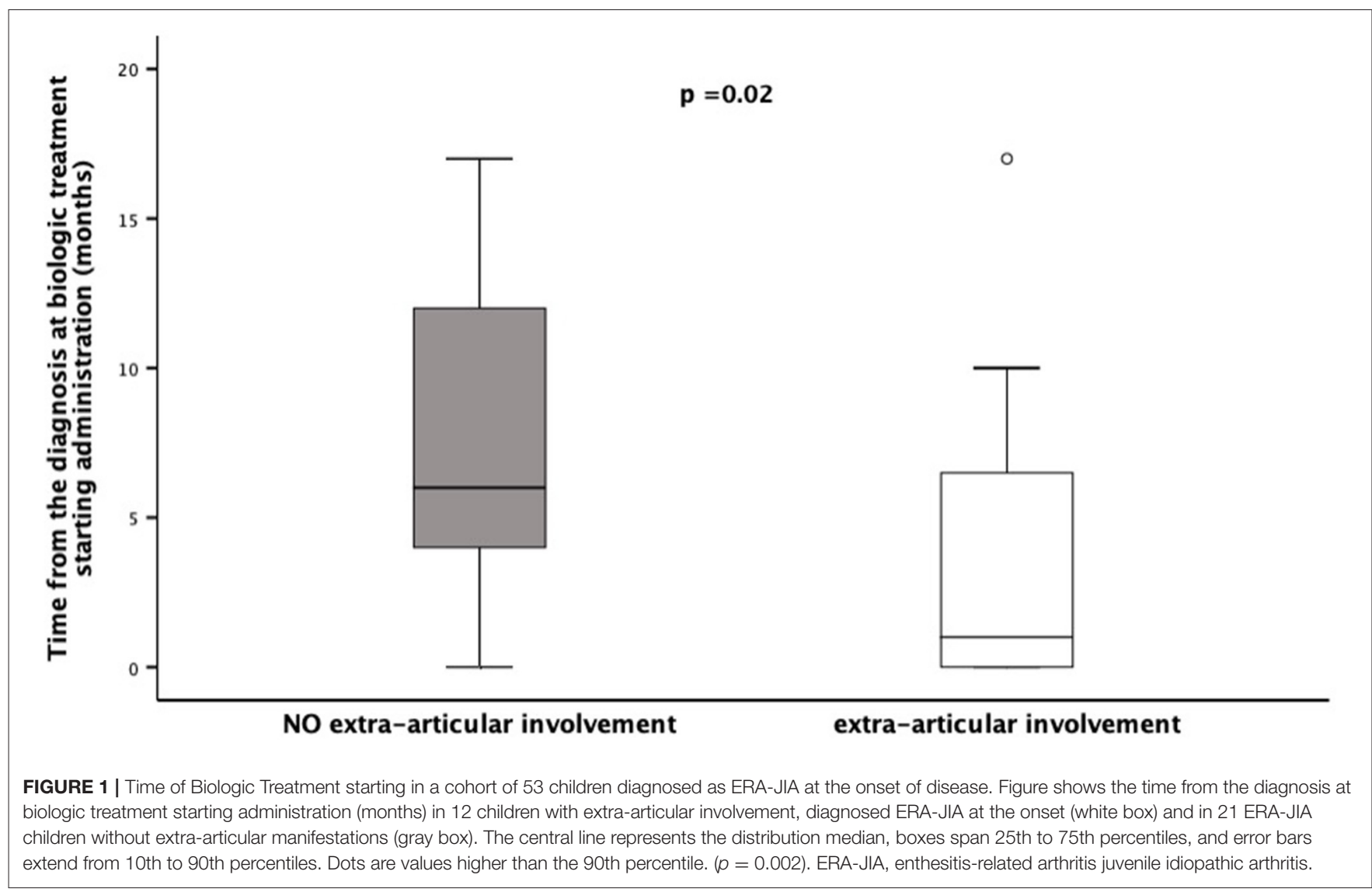

\section{DISCUSSION}

The central pathogenic event in various forms of arthritis in adults and children alike is certainly chronic inflammation of the synovial tissue and joint destruction $(30,31)$. In the specific types of the arthritis, such as spondyloarthritis in adults and ERA subtype of JIA in children, other structures, such as enthesis and/or axial joints, can be affected by inflammation in similar fashion $(11,32)$. Finally, the inflammatory process can spread beyond the musculoskeletal structures throughout the body causing the various extra-articular manifestations (33). However, for reasons not entirely clear, this scenario occurs in less than quarter of patients with SpA (34), while, to the best of our knowledge, our study was the first to report the incidence of several extra-articular manifestations in a single cohort of patients with ERA-JIA.

The results of our study showed that $26 \%$ of the enrolled subjects had and/or developed over the disease course extraarticular manifestations: three IBD, five uveitis, one uveitis associated with Crohn disease, four SAPHO syndrome and one celiac disease.

Therefore, eight children, representing the $15 \%$ of this monocentric cohort, and fulfilling the criteria for ERA at the onset of disease, developed additional clinical findings and were then reclassified accordingly: IBD-associated chronic arthritis, not included in ILAR criteria, and SAPHO syndrome.
In our monocentric cohort, it appears that the current ILAR criteria failed to properly classify the $15 \%$ of patients. The complexity of childhood rheumatic diseases makes them difficult to classify in coherent set criteria, as patients may present simultaneously a various range of manifestations shared by different disorders or develop over time additional findings. Mostly in childhood, the phenotype of each patient may evolve over time and extend beyond defined schemes, creating overlapping entities challenging to systemize while relying on the present knowledge (35). Although the ILAR criteria for ERA-JIA may fit jSpA peculiarities better than other classifications utilized mainly for adults, in these set of criteria, jSpA is covered by different subtypes of JIA, namely psoriatic arthritis, ERA and undifferentiated arthritis (1). However, certain phenotypes are excluded (e.g., reactive arthritis, arthritis associated with IBD) and the axial involvement is not specifically recognize, since the ERA subtype does not discriminate between axial and peripheral disease. Indeed, how to categorize JSpA still remains a debated and unsolved issue $(8,36,37)$.

Any attempt to classify SAPHO has been equally difficult, considering that the articular sings may be the first presentation of the latter cutaneous findings. While several authors consider this disorder as a group of autoinflammatory bone disorders others highlighted the strong link with SpA, especially in later life stage (38). 


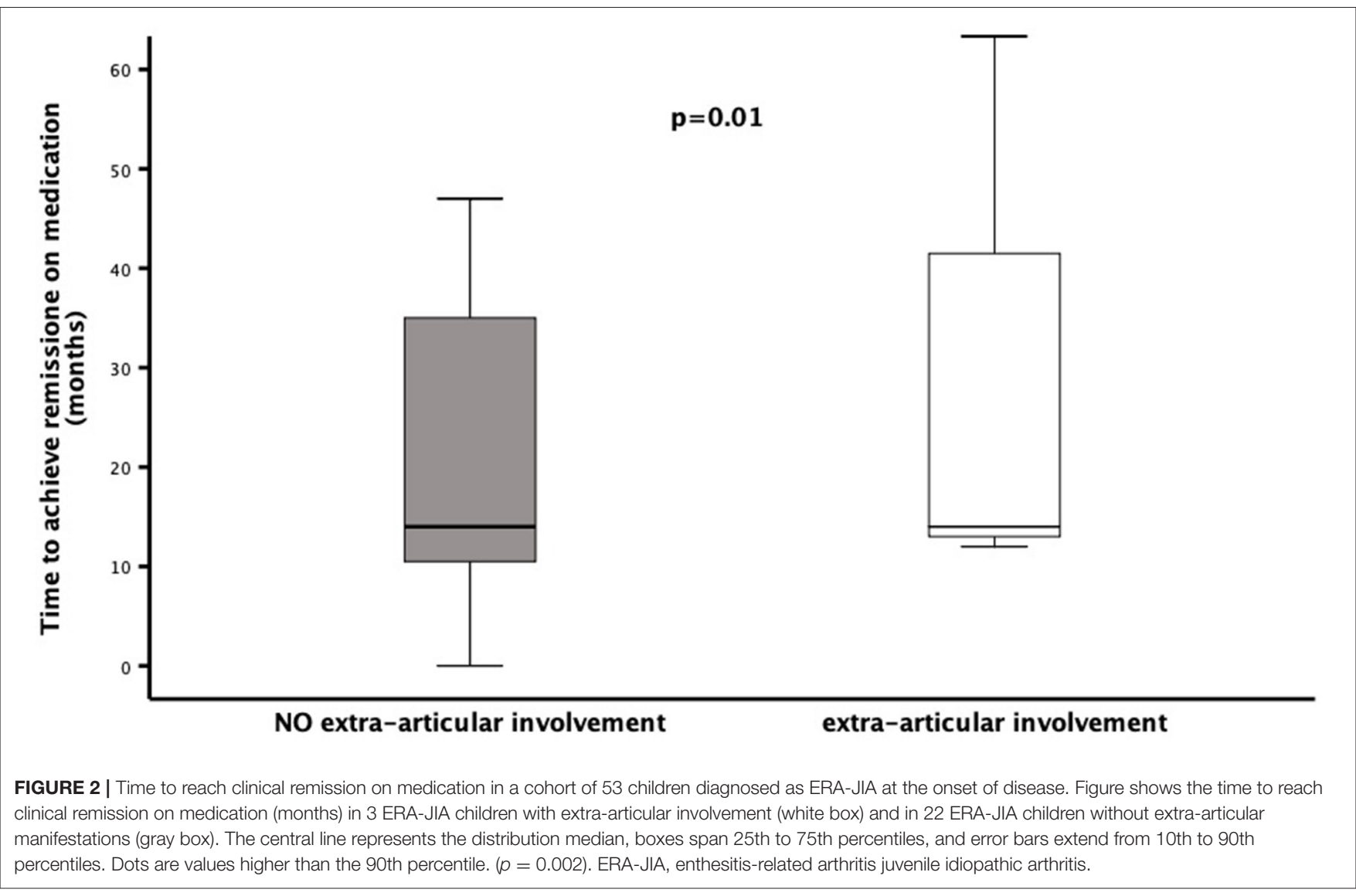

TABLE 2 | Comparison statistics stratifying into extra-articular- vs. non-extra-articular group.

\begin{tabular}{|c|c|c|c|}
\hline & $\begin{array}{l}\text { Non-extra- } \\
\text { articular } \\
\text { involvement }\end{array}$ & $\begin{array}{c}\text { Extra- } \\
\text { articular } \\
\text { involvement }\end{array}$ & $\chi^{2} \boldsymbol{P}$-values \\
\hline $\begin{array}{l}\text { Middle foot involvement } \\
(n / N, \%)\end{array}$ & $\begin{array}{l}18 / 39 \\
(46 \%)\end{array}$ & $\begin{array}{l}2 / 14 \\
(14 \%)\end{array}$ & $\begin{array}{l}4.45 \\
0.05\end{array}$ \\
\hline $\begin{array}{l}\text { Number of children receiving } \\
\text { biologic treatment } \\
(\mathrm{n} / \mathrm{N}, \%)\end{array}$ & $\begin{array}{l}21 / 39 \\
(54 \%)\end{array}$ & $\begin{array}{l}12 / 14 \\
(85 \%)\end{array}$ & $\begin{array}{l}4.45 \\
0.05\end{array}$ \\
\hline $\begin{array}{l}\text { Number of children } \\
\text { on clinical remission on } \\
\text { medication } \\
(n / N, \%)\end{array}$ & $\begin{array}{l}22 / 39 \\
(56 \%)\end{array}$ & $\begin{array}{l}3 / 14 \\
(22 \%)\end{array}$ & $\begin{array}{l}5.50 \\
0.03\end{array}$ \\
\hline $\begin{array}{l}\text { Number of children } \\
\text { on clinical remission at last } \\
\text { available follow-up } \\
(n / N, \%)\end{array}$ & $\begin{array}{l}26 / 39 \\
(67 \%)\end{array}$ & $\begin{array}{l}4 / 14 \\
(29 \%)\end{array}$ & $\begin{array}{l}6.08 \\
0.01\end{array}$ \\
\hline
\end{tabular}

Since some pathognomonic manifestation often occur late in disease course, the best chance to properly identify a disease may be a close clinical monitoring over time and reassessing the diagnosis when new sings/symptoms appear.

Interestingly, there were several important differences among patients with and without extra-articular manifestations in our cohort. Stratifying our cohort according to the presence/absence of extra-articular manifestations, we identified that the midfoot involvement in our cohort of ERA-JIA patients seems to correlate with no extra-articular manifestations, which was not observed in previous studies.

However, in accordance with recent literature, the midfoot involvement seems to be one of the key characteristics of ERA-JIA and may significantly affect the ERA prognosis. Phatak et al. (39), in an elegant prospective study, reported that the midfoot disease produced important functional limitation. During the course of the last years, numerous studies addressed the midfoot involvement as characteristic feature of ERA-JIA (40-42). The inflammation of midfoot in spondyloarthritis can engage pathological processes such as tarsal swelling, synovial inflammation, bone overgrowth, enchondral ossification, enthesophytosis, bone bridging, and finally ankylosis of the tarsal bones, leading to the distinctive form of the severe involvement of the feet, named ankylosing tarsitis (43). Interestingly, the similar changes are noticed in ankylosing spondylitis (AS), which is considered the differentiated form of spondyloarthritis, as opposite to the undifferentiated forms such as ERA-JIA. Therefore, the increased frequency of midfoot involvement in ERA-JIA patients, that do not develop extra-articular manifestations, could indicate the distinctive type of inflammation which spreads mainly 
throughout the musculoskeletal structures, avoiding the other body systems.

When our analysis was limited to the 45 children who still meet the ILARA criteria over the disease course, only the middle foot involvement remained statistically significant related to the ERA-JIA group with no extra-articular involvement. In our opinion, this result may strengths the hypothesis that middle foot involvement strictly belongs to the ERA phenotype, since other clinical data, even those included into the ILAR criteria were not able enough to clearly differentiate a group of ERA children, who at the onset met the ILAR criteria, and were then diagnosed with another different disease.

Another important finding in our cohort was that ERAJIA children that later developed extra-articular manifestations needed more frequently and preciously treatment with biologic agents. Moreover, these patients achieved belatedly and less frequently the clinical remission, on medication as well as without medication. Therefore, development of a different disease, such as IBD, as well as a systemic syndrome such as SAPHO, clearly modifies the prognosis and outcome in these children initially diagnosed as ERA-JIA according to ILAR criteria. Clinical experience from adult patients with AS reports a common association with extra-articular manifestations, although often subclinical (44). The presence of these comorbid conditions negatively affects the patients' quality of life and overall outcome (45). Emerging knowledge suggests that extraarticular manifestations in AS may be the expression of a unique inflammatory process involving the whole body (46). Therefore, the adoption of a therapeutical strategy that takes into account patients' symptoms in their entirety without focusing on a single area should be considered. In this perspective, an early recourse to a TNF-inhibitor (adalimumab and infliximab to be preferred above etanercept) for the management of AS with extra-articular manifestations and comorbid conditions may represent the most appropriate therapeutic approach (45-47).

According to several studies, ERA is associated with worse function, poorer quality of life, and increased pain intensity (48-50). In particular, HLA-B27 positivity, tarsitis, hip arthritis within the first 6 months, and older age of disease onset are associated with worse function, quality of life and pain (51-53). However, some of these studies reported some unexpected potential associations. Specifically, it has been reported that normal ESR correlates with a lower likelihood of attaining inactive disease (54). Interestingly, the authors suggested that TNF-alpha inhibitors may be more effective in patients whose active disease is accompanied by robust active systemic inflammation mirrored by raised inflammatory markers. Conversely, disease manifestations, such as joint pain and enthesalgia, that may not be strongly associated with systemic inflammation, tend to respond less well to TNFalpha inhibitors. In this complicated scenario, non-randomized studies showed that adding methotrexate to TNF-alpha inhibitors seems to be more effective than TNF-alpha inhibitors alone, which could be explained by different mechanisms of these two DMARDs $(55,56)$. Nevertheless, whatever the reason, these findings are in favor of the concept of the widespread disease in some patients with ERA-JIA.
We fully acknowledge the limitation of our results imposed by the small sample size which limits the strength of the conclusions. However, the present cohort represents the $10 \%$ of all JIA children followed at our unit over the course of 20 years, which is the percentage reported in other cohorts as well $(2,3)$.

Additionally, another advocated shortcoming might be that enthesitis was not confirmed by imaging studies, thus biasing the ERA-JIA diagnosis at the onset of the disease. However, none of the enrolled patients has been classified at diagnosis as ERA-JIA only by the clinical presence of enthesis, without a concomitant peripheral arthritis. Currently, according ILAR criteria, confirmation of Enthesitis by imaging is not a required criterion.

In conclusion, based on clinical observations from our cohort of patients, we hypothesize that there could be two distinctive disease phenotypes in JIA children with ERA, depending on the presence or absence of the extra-articular manifestations. Specifically, midfoot involvement was associated with ERAJIA diagnosis and the absence of extra-articular manifestations. Conversely, development of extra-articular manifestations over the time increases the chance of a different disease, such as Crohn disease and SAPHO syndrome, thus associated with worse prognosis, an early need for the use of biologic agents, longer time to achieve remission with and/or without medication. According to this mono-centric cohort, middle foot involvement seems to be a specific feature of JIA-ERA, since children with tarsitis, classified as ERA at the onset, still fulfilled the same criteria over the course of the disease.

While these findings might already have an important implication in the diagnostic and therapeutic approach to JIA patients with ERA, results from a prospective study involving larger multicenter cohort are mandatory for their confirmation.

\section{DATA AVAILABILITY STATEMENT}

The raw data supporting the conclusions of this article will be made available by the authors, without undue reservation.

\section{ETHICS STATEMENT}

Ethical review and approval was not required for the study on human participants in accordance with the local legislation and institutional requirements. Written informed consent from the participants' legal guardian/next of kin was not required to participate in this study in accordance with the national legislation and the institutional requirements.

\section{AUTHOR CONTRIBUTIONS}

IP designed the study and drafted the preliminary paper. MS and EM collected the patients' data. IM, MM, and LL participated in drafting the paper. FB helped in imaging assessment. GS performed statistical analysis, design the study, and finalized the paper. All authors contributed in writing the papers and approved the final draft of it. 


\section{REFERENCES}

1. Petty RE, Southwood TR, Manners P, Baum J, Glass DN, Goldenberg J, et al. International League of Associations for Rheumatology classification of juvenile idiopathic arthritis: second revision, Edmonton, 2001. J Rheumatol. (2004) 31:390-2.

2. Davies R, Carrasco R, Foster HE, Baildam EM, Chieng SE, Davidson JE, et al. Treatment prescribing patterns in patients with juvenile idiopathic arthritis (JIA): analysis from the UK childhood arthritis prospective study (CAPS). Semin Arthritis Rheum. (2016) 46:190-5. doi: 10.1016/j.semarthrit.2016.06.001

3. Guzman J, Oen K, Tucker LB, Huber AM, Shiff N, Boire G, et al. The outcomes of juvenile idiopathic arthritis in children managed with contemporary treatments: results from the ReACCh-Out cohort. Ann Rheum Dis. (2015) 74:1854-60. doi: 10.1136/annrheumdis-2015-eular.2400

4. Kunjir V, Venugopalan A, Chopra A. Profile of Indian patients with juvenile onset chronic inflammatory joint disease using the ILAR classification criteria for JIA: a community-based cohort study. J Rheumatol. (2010) 37:175662. doi: 10.3899/jrheum.090937

5. Shen C-C, Yeh K-W, Ou L-S, Yao T-C, Chen L-C, Huang J-L. Clinical features of children with juvenile idiopathic arthritis using the ILAR classification criteria: a community-based cohort study in Taiwan. J Microbiol Immunol Infect. (2013) 46:288-94. doi: 10.1016/j.jmii.2012. 03.006

6. Arkachaisri T, Tang SP, Daengsuwan T, Phongsamart G, Vilaiyuk S, Charuvanij S, et al. Paediatric rheumatology clinic population in Southeast Asia: are we different? Rheumatology. (2017) 56:390-8. doi: 10.1093/rheumatology/kew446

7. Tanya M, Teh KL, Das L, Hoh SF, Gao X, Arkachaisri T. Juvenile idiopathic arthritis in Southeast Asia: the Singapore experience over two decades. Clin Rheumatol. (2020) 39:3455-64. doi: 10.1007/s10067-020-05081-9

8. Tse SM, Laxer RM. New advances in juvenile spondyloarthritis. Nat Rev Rheumatol. (2012) 8:269-79. doi: 10.1038/nrrheum.2012.37

9. Foeldvari I. Ocular involvement in juvenile idiopathic arthritis: classification and treatment. Clin Rev Allergy Immunol. (2015) 49:271-7. doi: 10.1007/s12016-014-8436-9

10. Monnet D, Breban M, Hudry C, Dougados M, Brézin AP. Ophthalmic findings and frequency of extraocular manifestations in patients with HLA-B27 uveitis: a study of 175 cases. Ophthalmology. (2004) 111:8029. doi: 10.1016/j.ophtha.2003.07.011

11. Picco P, Gattorno M, Marchese N, Vignola S, Sormani MP, Barabino A, et al. Increased gut permeability in juvenile chronic arthritides. A multivariate analysis of the diagnostic parameters. Clin Exp Rheumatol. (2000) 18:773-8.

12. Öman A, Hansson T, Carlsson M, Berntson L. Evaluation of screening for coeliac disease in children with juvenile idiopathic arthritis. Acta paediatrica. (2019) 108:688-93. doi: 10.1111/apa.14598

13. Hayem G, Bouchaud-Chabot A, Benali K, Roux S, Palazzo E, Silbermann-Hoffman $\mathrm{O}$, et al. SAPHO syndrome: a long-term follow-up study of 120 cases. Semin Arthritis Rheum. (1999) 29:159-71. doi: 10.1016/S0049-0172(99)80027-4

14. Colina M, Govoni M, Orzincolo C, Trotta F. Clinical and radiologic evolution of synovitis, acne, pustulosis, hyperostosis, and osteitis syndrome: a single center study of a cohort of 71 subjects. Semin Arthritis Rheum. (2009) 61:813-21. doi: 10.1002/art. 24540

15. Huppertz H, Voigt I, Müller-Scholden J, Sandhage K. Cardiac manifestations in patients with HLA B27-associated juvenile arthritis. Pediatr Cardiol. (2000) 21:141-7. doi: 10.1007/s002469910023

16. Koca B, Sahin S, Adrovic A, Barut K, Kasapcopur O. Cardiac involvement in juvenile idiopathic arthritis. Rheumatol Int. (2017) 37:137-42. doi: 10.1007/s00296-016-3534-z

17. Oguz D, Ocal B, Ertan U, Narin H, Karademir S, Senocak F. Left ventricular diastolic functions in juvenile rheumatoid arthritis. Pediatr Cardiol. (2000) 21:374-7. doi: 10.1007/s002460010084

18. Brambila-Tapia AJ, Rocha-Muñoz AD, Gonzalez-Lopez L, Vázquez-DelMercado M, Salazar-Páramo M, Dávalos-Rodríguez IP, et al. Pulmonary function in ankylosing spondylitis: association with clinical variables. Rheumatol Int. (2013) 33:2351-8. doi: 10.1007/s00296-013-2723-2
19. Rodrigues CE, Vieira WP, Bortoluzzo AB, Gonçalves CR, da Silva JA, Ximenes $\mathrm{AC}$, et al. Low prevalence of renal, cardiac, pulmonary, and neurological extraarticular clinical manifestations in spondyloarthritis: analysis of the Brazilian Registry of Spondyloarthritis. Rev Bras Reumatol. (2012) 52:375-83.

20. Fink CW. Proposal for the development of classification criteria for idiopathic arthritides of childhood. J Rheumatol. (1995) 22:1566-9.

21. Rosenberg AM, Petty RE. A syndrome of seronegative enthesopathy and arthropathy in children. Arthritis Rheum. (1982) 25:10417. doi: 10.1002/art.1780250902

22. Heuft-Dorenbosch L, Spoorenberg A, van Tubergen A, Landewé R, Ver Tempel H, Mielants $\mathrm{H}$, et al. Assessment of enthesitis in ankylosing spondylitis. Ann Rheum Dis. (2003) 62:127-32. doi: 10.1136/ard.62.2.127

23. Sieper J, van der Heijde D, Landewé R, Brandt J, Burgos-Vagas R, CollantesEstevez E, et al. New criteria for inflammatory back pain in patients with chronic back pain: a real patient exercise by experts from the Assessment of SpondyloArthritis international Society (ASAS). Ann Rheum Dis. (2009) 68:784-8. doi: 10.1136/ard.2008.101501

24. Giannini EH, Ruperto N, Ravelli A, Lovell DJ, Felson DT, Martini A. Preliminary definition of improvement in juvenile arthritis. Arthritis Rheum. (1997) 40:1202-9.

25. Wallace CA, Ravelli A, Huang B, Giannini EH. Preliminary validation of clinical remission criteria using the OMERACT filter for select categories of juvenile idiopathic arthritis. J Rheumatol. (2006) 33:789-95.

26. Bollow M, Biedermann T, Kannenberg J, Paris S, Schauer-Petrowski $\mathrm{C}$, Minden $\mathrm{K}$, et al. Use of dynamic magnetic resonance imaging to detect sacroiliitis in HLA-B27 positive and negative children with juvenile arthritides. J Rheumatol. (1998) 25:556-64. doi: 10.1007/s002560050446

27. Bollow M, Braun J, Hamm B, Eggens U, Schilling A, König H, et al. Early sacroiliitis in patients with spondyloarthropathy: evaluation with dynamic gadolinium-enhanced MR imaging. Radiology. (1995) 194:52936. doi: 10.1148/radiology.194.2.7824736

28. Rudwaleit M, Jurik AG, Hermann K-GA, Landewé R, van der Heijde D, Baraliakos X, et al. Defining active sacroiliitis on magnetic resonance imaging (MRI) for classification of axial spondyloarthritis: a consensual approach by the ASAS/OMERACT MRI group. Ann Rheum Dis. (2009) 68:15207. doi: 10.1136/ard.2009.110767

29. van der Heijde DM, Landewé RB, Hermann K-GA, Jurik A-G, Maksymowych WP, Rudwaleit M, et al. Application of the OMERACT filter to scoring methods for magnetic resonance imaging of the sacroiliac joints and the spine. Recommendations for a research agenda at OMERACT 7.J Rheumatol. (2005) 32:2042-7.

30. Smolen JS, Aletaha D, McInnes IB. Rheumatoid arthritis. Lancet. (2016) 388:2023-38. doi: 10.1016/S0140-6736(16)30173-8

31. Prakken B, Albani S, Martini A. Juvenile idiopathic arthritis. Lancet. (2011) 377:2138-49. doi: 10.1016/S0140-6736(11)60244-4

32. Tam L-S, Gu J, Yu D. Pathogenesis of ankylosing spondylitis. Nat Rev Rheumatol. (2010) 6:399-405. doi: 10.1038/nrrheum.2010.79

33. Brophy S, Calin A. Ankylosing spondylitis: interaction between genes, joints, age at onset, and disease expression. J Rheumatol. (2001) 28:2283-8.

34. Bengtsson K, Forsblad-d'Elia H, Deminger A, Klingberg E, Dehlin M, Exarchou $\mathrm{S}$, et al. Incidence of extra-articular manifestations in ankylosing spondylitis, psoriatic arthritis and undifferentiated spondyloarthritis: results from a national register-based cohort study. Rheumatology (Oxford). (2020). doi: 10.1093/rheumatology/keaa692. [Epub ahead of print].

35. Maniscalco V, Marrani E, Lamot L, Lionetti P, Simonini G. The conundrum of juvenile spondyloarthritis classification: many names for a single disease? Lesson learned from an instructive clinical case. Int J Rheum Dis. (2020) 23:1248-51. doi: 10.1111/1756-185X.13922

36. Colbert RA. Classification of juvenile spondyloarthritis: enthesitisrelated arthritis and beyond. Nat Rev Rheumatol. (2010) 6:477-85. doi: 10.1038/nrrheum.2010.103

37. Adrovic A, Sezen M, Barut K, Sahin S, Acikel C, Demirkaya E, et al. The performance of classification criteria for juvenile spondyloarthropathies. Rheumatol Int. (2017) 37:2013-8. doi: 10.1007/s00296-017-3837-8

38. Hofmann SR, Kapplusch F, Girschick HJ, Morbach H, Pablik J, Ferguson PJ, et al. Chronic Recurrent multifocal osteomyelitis (CRMO): presentation, pathogenesis, and treatment. Curr Osteoporos Rep. (2017) 15:542-54. doi: 10.1007/s11914-017-0405-9 
39. Phatak S, Mohindra N, Zanwar A, Aggarwal A. Prominent midfoot involvement in children with enthesitis-related arthritis category of juvenile idiopathic arthritis. Clin Rheumatol. (2017) 36:1737-45. doi: 10.1007/s10067-017-3733-3

40. Burgos-Vargas R, Pacheco-Tena C, Vázquez-Mellado J. A short-term followup of enthesitis and arthritis in the active phase of juvenile onset spondyloarthropathies. Clin Exp Rheumatol. (2002) 20:727-31.

41. Adrovic A, Barut K, Sahin S, Kasapcopur O. Juvenile spondyloarthropathies. Curr Rheumatol Rep. (2016) 18:55. doi: 10.1007/s11926-016-0603-y

42. Aquino MR, Tse SM, Gupta S, Rachlis AC, Stimec J. Whole-body MRI of juvenile spondyloarthritis: protocols and pictorial review of characteristic patterns. Pediatr Radiol. (2015) 45:754-62. doi: 10.1007/s00247-015-3319-7

43. Pacheco-Tena C, Pérez-Tamayo R, Pineda C, González-Chávez SA, Quiñonez-Flores C, Ugalde Vitelly A, et al. Bone lineage proteins in the entheses of the midfoot in patients with spondyloarthritis. J Rheumatol. (2015) 42:630-7. doi: 10.3899/jrheum.140218

44. Vander Cruyssen B, Ribbens C, Boonen A, Mielants H, Vlam K de, Lenaerts J, et al. The epidemiology of ankylosing spondylitis and the commencement of anti-TNF therapy in daily rheumatology practice. Ann Rheum Dis. (2007) 66:1072-7. doi: 10.1136/ard.2006.064543

45. Smolen JS, Braun J, Dougados M, Emery P, Fitzgerald O, Helliwell P, et al. Treating spondyloarthritis, including ankylosing spondylitis and psoriatic arthritis, to target: recommendations of an international task force. Ann Rheum Dis. (2014) 73:6-16. doi: 10.1136/annrheumdis-2013-2 03419

46. Elewaut D, Matucci-Cerinic M. Treatment of ankylosing spondylitis and extra-articular manifestations in everyday rheumatology practice. Rheumatology. (2009) 48:1029-35. doi: 10.1093/rheumatology/ kep 146

47. van den Bosch F. A survey of European and Canadian rheumatologists regarding the treatment of patients with ankylosing spondylitis and extra-articular manifestations. Clin Rheumatol. (2010) 29:281-8. doi: 10.1007/s10067-009-1317-6

48. Weiß A, Minden K, Listing J, Foeldvari I, Sieper J, Rudwaleit M. Course of patients with juvenile spondyloarthritis during 4 years of observation, juvenile part of GESPIC. RMD Open. (2017) 3:e000366. doi: 10.1136/rmdopen-2016-000366
49. Flatø B, Hoffmann-Vold A-M, Reiff A, Førre Ø, Lien G, Vinje O. Long-term outcome and prognostic factors in enthesitis-related arthritis: a case-control study. Arthritis Rheum. (2006) 54:3573-82. doi: 10.1002/art.22181

50. Minden K, Niewerth M, Listing J, Biedermann T, Bollow M, Schöntube $\mathrm{M}$, et al. Long-term outcome in patients with juvenile idiopathic arthritis. Arthritis Rheum. (2002) 46:2392-401. doi: 10.1002/art.10444

51. Gmuca S, Weiss PF. Evaluation and treatment of childhood enthesitisrelated arthritis. Curr Treat Options Rheumatol. (2015) 1:350-64. doi: 10.1007/s40674-015-0027-2

52. Weiss PF. Diagnosis and treatment of enthesitis-related arthritis. Adolesc Health Med Ther. (2012) 2012:67-74. doi: 10.2147/AHMT.S25872

53. Weiss PF. Evaluation and treatment of enthesitis-related arthritis. Curr Med Lit Rheumatol. (2013) 32:33-41.

54. Donnithorne KJ, Cron RQ, Beukelman T. Attainment of inactive disease status following initiation of TNF- $\alpha$ inhibitor therapy for juvenile idiopathic arthritis: enthesitis-related arthritis predicts persistent active disease. J Rheumatol. (2011) 38:2675-81. doi: 10.3899/jrheum.110427

55. Horneff G, Bock F de, Foeldvari I, Girschick HJ, Michels H, Moebius D, et al Safety and efficacy of combination of etanercept and methotrexate compared to treatment with etanercept only in patients with juvenile idiopathic arthritis (JIA): preliminary data from the German JIA Registry. Ann Rheum Dis. (2009) 68:519-25. doi: 10.1136/ard.2007.087593

56. Papsdorf V, Horneff G. Complete control of disease activity and remission induced by treatment with etanercept in juvenile idiopathic arthritis. Rheumatology. (2011) 50:214-21. doi: 10.1093/rheumatology/keq292

Conflict of Interest: The authors declare that the research was conducted in the absence of any commercial or financial relationships that could be construed as a potential conflict of interest.

Copyright (c) 2021 Pagnini, Scavone, Maccora, Mastrolia, Marrani, Bertini, Lamot and Simonini. This is an open-access article distributed under the terms of the Creative Commons Attribution License (CC BY). The use, distribution or reproduction in other forums is permitted, provided the original author $(s)$ and the copyright owner(s) are credited and that the original publication in this journal is cited, in accordance with accepted academic practice. No use, distribution or reproduction is permitted which does not comply with these terms. 